\title{
English Language in Pakistan: Expansion and Resulting Implications
}

\author{
Syeda Bushra Zaidi * \\ Sajida Zaki ${ }^{\dagger}$
}

\begin{abstract}
From sociolinguistic or anthropological perspective, Pakistan is classified as a multilingual context with most people speaking one native or regional language alongside Urdu which is the national language. With respect to English, Pakistan is a second language context which implies that the language is institutionalized and enjoying the privileged status of being the official language. This thematic paper is an attempt to review the arrival and augmentation of English language in Pakistan both before and after its creation. The chronological description is carried out in order to identify the consequences of this spread and to link them with possible future developments and implications. Some key themes covered in the paper include a brief historical overview of English language from how it was introduced to the manner in which it has developed over the years especially in relation to various language and educational policies. Based on the critical review of the literature presented in the paper there seems to be no threat to English in Pakistan a prediction true for the language globally as well. The status of English, as it globally elevates, will continue spreading and prospering in Pakistan as well enriching the Pakistani English variety that has already born and is being studied and codified. However, this process may take long due to the instability of governing policies and law-makers. A serious concern for researchers and people in general, however, will continue being the endangered and indigenous varieties that may continue being under considerable pressure from the prestigious varieties.
\end{abstract}

Keywords: English language, consequences, language spread, implications, endangered languages, indigenous languages.

\section{Introduction}

\section{Theme of the Paper}

This paper outlines a study based on a detailed literature survey about English in Pakistan with the purpose of mapping its spread in future alongside the possible consequences. These conclusions are based on the premises provided by the role that English language has essayed for itself in Pakistan from the country's creation to the contemporary times.

\section{Background}

English language has remained influential in Pakistan. Its role as a lingua franca and earlier as the official language has given it a prominent position in a multilingual landscape

\footnotetext{
* MS Fellow (Applied Linguistics), Department of Humanities, NED University of Engineering \& Technology Karachi, Pakistan. Email: bushrazaidi@icloud.com

${ }^{\dagger}$ Professor \& Chairperson, Department of Humanities, NED University of Engineering \& Technology Karachi, Pakistan. Email: drzaki@neduet.edu.pk
} 
of Pakistan. It functions in a multilingual context of use where how it has harmonized as well as disturbed the linguistic competition is of stark importance. Not only this, it has gone through a roller-coaster ride over the years in Pakistan. However, it has never been completely removed and disregarded. Ever since Pakistan gained independence from the British rule, the English language has never left Pakistan solely on its local languages. It has always accompanied other regional and local languages at all levels. To study the consequences of the spread of English, it is essential to first understand the status and role of English in the present-day Pakistan. This would be possible only after describing the country's linguistic landscape and the history of the English language arrival and spread here.

\section{The Status of English in Pakistan}

Recently, Coleman (2010, 2011); Seargeant and Erling (2011); Wedell (2011) and others have worked on the assumptions held about the functional, practical and utilitarian value of English, especially in the countries that are developing. As a result, they have carefully identified the following three roles English has been playing in the developing countries. These roles include: positive, negative and neutral roles. According to Kachru (1986), English in any multilingual context has two major purposes: First, it serves to be the language of administration, that is, it serves as the official language of the state, and secondly, it performs its functions as the language of mass communication.

The role of English in Pakistan is ever more multiplex as it is the state and official language, and also of the military and higher education. Power is associated with English and it has been the language of an elite class that has influenced the country since its birth. A distinctive Pakistani variety of English exists and is being codified (Rahman, 2010). Conservative groups who resist English can also be found across the country.

Persistently, various language policies and linguistic conflicts have aimed to impose the choice of Urdu as the official language. However, it has been difficult to undermine English from its supreme position. Article 251 of the 1973 constitution, which is still enforcing in 2016 with certain amendments, declares Urdu as the national and English as the official language of Pakistan. It stated:

- Clause 1. The National Language of Pakistan is Urdu, and arrangements shall be made for its being used for official and other purposes within fifteen years from the commencing day.

- Clause 2. Subject to clause (1) the English language may be used for official purposes until arrangements are made for its replacement by Urdu.

In compliance with the constitution and considering the impact of globalization on all nations, Pakistan's educational policy favours English to be introduced as a compulsory subject from grade 1 . The higher education commission also positively inclines towards English being the language of education. The policies, despite their efficacy, are unable to produce desirable outcomes in all domains of English language usage. People, especially educators, are ill-equipped in delivering the efficient results required. 
The study on 'Skills disconnect in Sindh', conducted by the British Council Pakistan, Pakistan Institute of Development Economics, Islamabad (2015) suggested that, of the four major skills gaps that are hindering Sindh's economic development, English language skills is the first one. In another study, 'Can English medium education work in Pakistan? Lessons from Punjab', conducted by the Punjab English Education and Language Institute (PEELI) under British Council Pakistan (2013) in Punjab province, the report suggested that Punjab teachers were ill-equipped to deliver the English medium policy and the report also makes some suggestions for the policy makers as well. The purpose of discussing the findings of the two studies conducted in the two most populous provinces of Pakistan is to shed light on the situation or status of English in Pakistan.

In 2010, the provincial cabinet committee of Khyber Pakhtunkhwa (KP) agreed unanimously upon a multilingual solution that placed emphasis on the mother tongue education. According to this, Pashto, Hindko, Siraiki, Khowar and Kohistani were to be implemented as part of compulsory courses in both state and non-state run schools. However, in 2014, the new provincial government in order to get in line with the educational and constitutional policy switched the MoI in public sector schools from Urdu to English. The reasons presented for such changes were aimed at bringing uniformity in education in private and public sector education systems. The findings of the researches conducted on this subject in KP shows that parents had strong inclinations towards education in the mother tongue. In lieu of this, out of the many other recommendations of the recommendations of a British Council Pakistan (2012) that focused on a case study in KP and its consultations and policy dialogues, one of the results was: "There is evidence that many people are strongly attached to their languages and wish to educate their children through those languages". The findings of another survey (ASER, 2012), that involved 13,702 households of KP, showed results that $45 \%$ wanted Pashto as the MoI whereas only 39\% chose Urdu as the MoI in schools. These surveys are indicative of the unsteady and hasty decision of the KP government to switch the MoI to English which is not in accord with the preferences of the parents and other stakeholders in KP. Apart from this, the teachers are still not well trained in Urdu in the province, teachers being well trained in English seems to be only a desire.

As a result of such educational and language policies and their ineffectiveness and non-implementation in reality, the Pakistani population is left divided in different groups with respect to English language proficiency. Shamim (2011) suggests that the current educational policies regarding the choice of language in education system in Pakistan as being one of 'linguistic apartheid'. Moreover, Rahman (2004) has also talked of 'educational apartheid' that is segregating English medium elite schools and the Urdu medium schools for the masses creating a polarized educational situation and system. Such a cataclysmic situation has been described by Rahman as follows:

“By supporting English through a parallel system of elite schooling, Pakistan's ruling elite acts as an ally of the forces of globalization at least as far as the hegemony of English is concerned. The major consequence of this policy is the weakening of local languages and the lowering of their status. This, in turn, opposes linguistic and cultural diversity, weakens the 'have - nots' even 
further and increases poverty by leaving the best - paid jobs in the hands of the international elite and the English - using elite of the peripheries"' (Rahman, 2010).

\section{The Language Landscape of Pakistan}

The language landscape of Pakistan is neither too vast nor too narrow. Pakistan has an approximate of $<73>$ language and there are at least 73 languages in Pakistan (Mehboob, 2002). Among these, 8 are non-indigenous and 65 are indigenous (Ethnologue, 1989). The geographical distribution of Pakistan is not only in terms of the contour lines on the map but also with respect to the languages spread across the country. Urdu, being the official language of Pakistan, enjoys the official status along with English which is the coofficial language. Pakistan is divided into the following administrative units: 4 provinces, 1 federal-capital territory, 2 autonomous and disputed territories, and a group of federally administered tribal areas. In addition to Urdu, only one language in each province is recognized. Many minority languages remain unrecognized. Such non-recognition of regional languages in Pakistan is leading to language disloyalty and linguistic death; as in the case of Domaaki the speaker of which have now reduced only to a mere 500 (Mehboob, 2002), Kundal Shahi which has only 100 to 400 speakers left (Rehman \& Baart, 2005), or Badeshi which is now already a dead language. Users of these languages find their language to be unuseful to them as it does not bring them any charm, wealth or benefit to progress and proceed in life. In order to achieve success, they have to be proficient in either English or Urdu (or both); therefore, they shun the use of their languages to be competent in Urdu or any other more powerful regional language. The six major languages spoken in Pakistan are presented in the Figure 1.

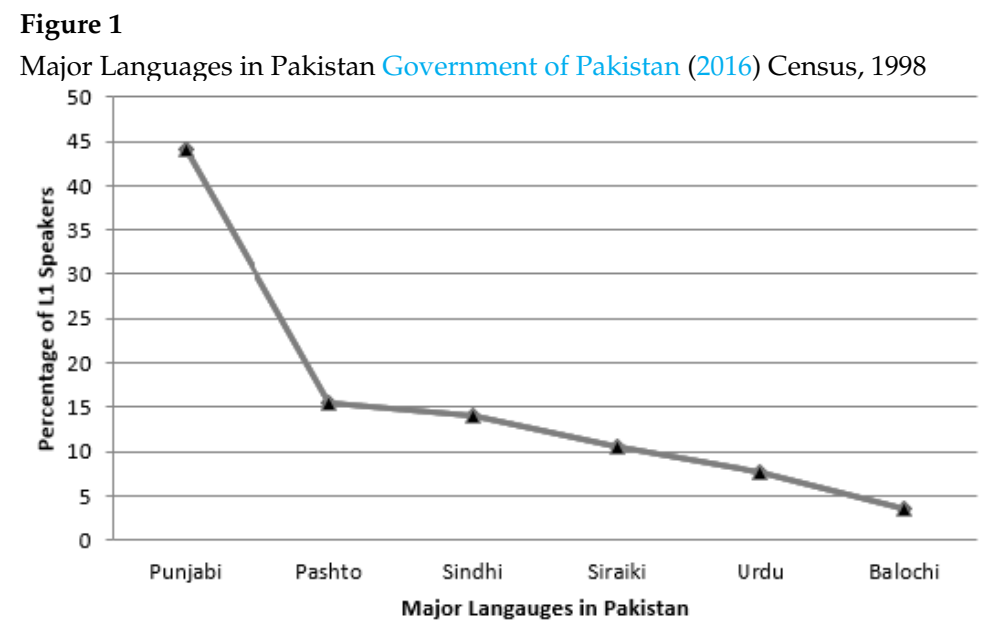

The reason for choosing these languages is the status of each language with respect to its number of speakers and their socio-geographical widespread fame Ethnologue (1989). 
Figure 2, which is an adaptation of De Swaan's Global Language System (as cited in Galloway and Rose (2015)), is an attempt to explain the current linguistic distribution in Pakistan. The figure shows English and Urdu as the Hyper-central languages which enjoy the prestigious status, Urdu because of being the national language has nationalistic sentiments attached to it, and English being the co-official language which is now taken as a key to success. Both these languages have a high status as compared to the other languages with which they co-exist. This co-existence of two prestigious languages descends the status of the other languages. Thence, the Super-central languages are the provincial languages which enjoy the official status within a province. They too exist with other languages which are then categorized as the Central languages which are in no danger of dying sometime soon. The languages grouped in the Peripheral languages include all the other languages which are not named in the figure. These are the endangered languages that are losing the potential to attract a number of speakers because of the prestige and profits the other central, super-central, or hyper-central languages are offering.

Figure 2

An Adaptation of De Swaan's Global Language System (Source: De Swaan, 2001, pp. 5-6)

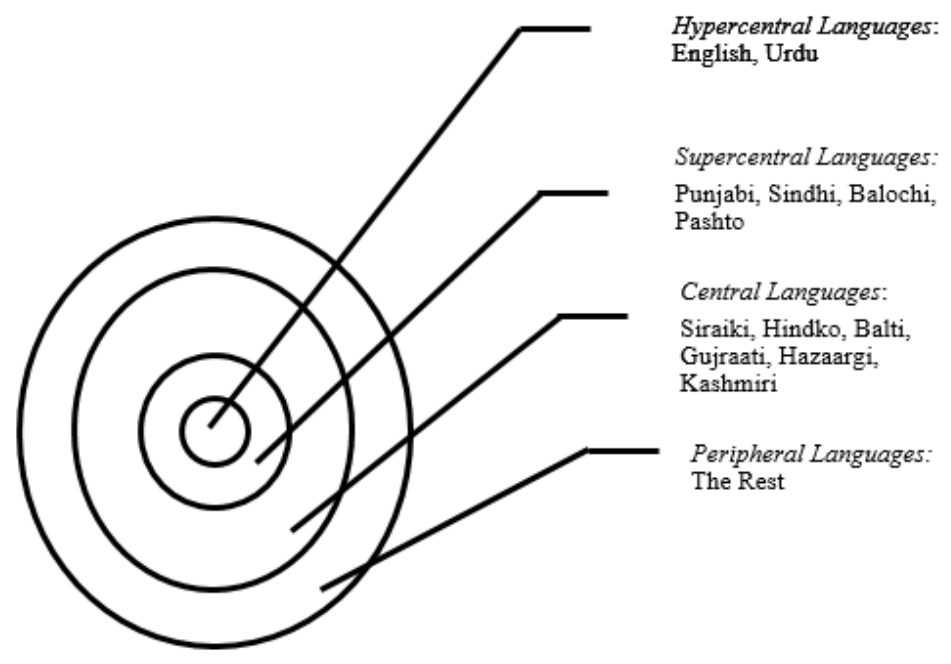

English in Pakistan: A Historical Overview

\section{Under the British Rule}

The English language in Pakistan was introduced long before the country gained its independence and separated from the subcontinent (Pakistan, India and Bangladesh combined). English was brought to the sub-continent with the colonization of the then India by the British. Before the partition, Persian was the language of the court, the elites, and it also symbolized the Muslim culture. Thence it was the official language of the Moghals. Persian was the supreme language and the role of it along with and other vernaculars 
was very well prescribed and established in the pre-British era. Other than this, there was no apparent linguistic need for a language switch or domain shift in the distribution and functions of these languages (Mehboob, 2002). When the British invaded India, they brought with them their language which was initially meant to be taught to 'civilize' the 'uncivilized' Indians. The British believed that the natives lacked culture and values and by introducing English to them, or rather by Englishizing and Christianizing them; they would be cultured and civilized. Therefore, the Britons bringing their language to the sub-continent and intentionally replacing Persian, which was not needed at that time, of course had extra-linguistic incentives. According to Rubin (1983), such extra and nonlinguistic policies indicate the deliberate changing in the local distribution of the usage of the local languages that do not have any linguistic purposes.

A language gains a higher status for one chief reason: the political power of its people, especially their military power (Crystal as cited in Graddol (1997)). If there is any change in the distribution of usage indigenous languages, it could also be proportionally symbolic of a simultaneous change in the power structure. With the shift of a society's preferred and most used language from one to the other, the power also shifts from one hand to the other. Persian was symbolic of the Muslim rulers in the sub-continent. In 1835 , the switch in the official language also reflected the shift in and switch of the power holders and became reflective of the British control over India. Many claims that such language changes were planned through their language policies by the British, as this term is referred to by Cooper (1989), "language planning refers to deliberate efforts to influence the behaviour of others with respect to the acquisition, structure, or functional allocation of their language codes." Assessed on these parameters, the British policy was highly influential and effective. Even 69 years after the end of the English rule in the subcontinent, the English language flourishes and blossoms as an indigenized or nativized variety with local mixing, variations, and uses. Similarly, as it was during the British rule, the English language, even today, remains a key for entering into supreme bureaucratic, governmental, high social positions.

\section{Post-independence Pakistan}

Table 1 summarizes the language policies in Pakistan implemented since 1947 to date. The following is a description and attempt to highlight problems (if any) in each policy.

Just as Pakistan gained its independence, a three-language structure policy was announced for the state. With English being the official language, Urdu the national, and a provincial language for each province, it was stated that Urdu would replace English once developed for such a status. Geographically, the state of Pakistan was separated into two exclaves: West and East Pakistan separated by a huge distance of $1600 \mathrm{kms}$ created problems not only for the smooth running of administration but also for developing a uniform language policy. Bengali was the majority language of East Pakistan and according to the 1951 census, Bengalis' population was $54.6 \%$ of the total population of Pakistan. However, the prominent leaders of the Pakistan Movement supported and promoted Urdu as the only national language of Pakistan. 
Table 2

Language policies in Pakistan from 1947 to 2016

\begin{tabular}{|c|c|}
\hline Year & Language Policy \\
\hline 1947 & Three language structure: Urdu as national, English as official, one provincial language \\
\hline 1948 & $\begin{array}{l}\text { Urdu declared as the only national language\& as MoI at primary level, English as MoI for higher levels } \\
\text { Urdu to substitute English in official domains once developed in ten years }\end{array}$ \\
\hline 1958 & $\begin{array}{l}\text { English implemented as MoI in cadets, mandatory for qualified personnel to know English } \\
\text { English taught as compulsory subject in state-run schools, private English-medium schools allowed to flourish } \\
\text { Lease of } 15 \text { years granted for Urdu to substitute English }\end{array}$ \\
\hline 1971 & End of Urdu-Bengali linguistic conflicts; Urdu harmoniously declared as the state's national language \\
\hline 1973 & $\begin{array}{l}\text { Restatement of the three-structure language policy: English as official, Urdu as national \& a provincial language } \\
\text { Another lease of } 15 \text { years was granted for Urdu to replace English }\end{array}$ \\
\hline 1977 & $\begin{array}{l}\text { Institutionalization of only Urdu across the country } \\
\text { Imposition of Urdu as MoI in state-run schools, English introduced in grade } 6 \\
\text { Arabic introduced as a compulsory subject }\end{array}$ \\
\hline 1987 & Urdu only policies retracted \\
\hline 1989 & $\begin{array}{l}\text { English taught as mandatory subject from grade } 1 \\
\text { Non-state run schools continued with only English syllabi }\end{array}$ \\
\hline 1998 & New education policy announced with no statement regarding the language policy \\
\hline 2007 & $\begin{array}{l}\text { A 'white paper' issued that stressed English to be taught from grade 1, mathematics and science to be taught } \\
\text { through English from grade 6" }\end{array}$ \\
\hline 2009 & Science and mathematics to be taught through English from 2014 \\
\hline 2015 & Official notification passed by the Supreme Court to make Urdu the official language \\
\hline 2016 & Policy under formulation to make Urdu the only official language \\
\hline
\end{tabular}

Quaid-i-Azam Mohammad Ali Jinnah, the founder of Pakistan, in his speech in Bengal said, "let me make it clear to you that the State Language of Pakistan is going to be Urdu and no other language. Anyone who tries to mislead you is really the enemy of Pakistan" (Jinnah, 1989). This speech created friction between the two distanced parts of Pakistan: East and West. Quaid's attitude and policy towards Bengali was then symbolically taken as a symbol of a deliberate action to subdue the Bengali values, norms and cultures. The language issues and linguistic conflicts of Urdu and Bengali, however, were not saturated, and the government's inclination towards Urdu language, by declaring it as the $\mathrm{MoI}^{1}$ at primary levels and English as the language of higher education, subdued the status of Bengali agonizing the East Pakistan's Bengali majority population. Despite the conflicts, the government adhered to its already declared language policy and it was expected that by the year 1958, Urdu would be developed and would replace English in all official and higher education domains. However, with the first martial law in 1958, Pakistan saw its first pro-English government. The status of English was elevated by making it mandatory for qualified personnel to learn and know. It was not only implemented as the MoI in cadets, but also taught as a compulsory subject in the state-run public sector schools. Private sector schools were allowed to flourish with English being their MoI. Howbeit, due to the pro-Urdu right wing activities, public sectors remained deprived of English as their MoI. On the other hand, English medium schools were promoted and thus flourished. Such division and discrimination continued creating the "caste-like" dif-

\footnotetext{
${ }^{1}$ MoI: Medium of instruction
} 
ferences between the two groups, just as it had happened during the British rule. The job opportunities were such that the group having greater competency in English language were trained to govern while the Urdu medium schools produced the subordinate staff. Powell (2002) writes: “A 1958 National Education Commission under Ayub Khan's military regime (1958-69) urged the promotion of unity through Urdu, but since the civil and military bureaucracies were English-educated and in favour of social modernization, they sent out mixed messages." Moreover, since the Urdu language was not developed enough to replace English, a lease of fifteen years was granted with the hope that by the year 1974, Urdu would replace English and become the only official language of Pakistan. The government ignored the Urdu-Bengali controversy and focused on the promotion of English language without changing the state's language policy. Over the years, the interexclave conflicts over socio-linguistic and geo-political issues aggravated and resulted in the separation of East from West Pakistan in the year 1971. The independence of East Pakistan, present day Bangladesh, simplified the Urdu-Bengali controversy; therefore, resulting in the harmonious agreement upon Urdu as the state's only national language in the 1973 constitution. The 1973 constitution is of crucial importance as it is still enforcing, with certain amendments, in 2016 (present day). It restated the three-language structure maintaining Urdu as the national, English as the official, and a provincial language for each province which is to be taught as a subject alongside English and Urdu. Except for Sindhi language, no other provincial language is taught as a compulsory subject in Pakistan. Therefore, it can be said that at the tertiary level the constitution of Pakistan supports and promotes multilingualism but at the heart of it, and actually, it promotes bilingualism (of Urdu and English) in a multilingual country.

Since the government in 1958 stated that Urdu would replace English 1974 once developed and elevated to such a status, the arrangements for Urdu's development were still not made. Hence, in 1973 another lease of fifteen years was granted to develop Urdu for it being used for official and other purposes from the commencing day.

The year 1977 saw a major shift in the language policy. With the government being pro-Urdu, the Urdu language policy was promoted. Urdu was institutionalized across the country and was imposed as the MoI in government schools with English not being introduced up till 6th grade. In addition to this, Arabic language was introduced as a compulsory subject. The government's rules for the Urdu only policy were strict for the public-sector schools; however, on the contrary, English medium elite schools remained unaffected, given legal protection and were not stopped from operating. This dual policy of the government for public and private sector schools was highly criticized. By 1987, some of the Urdu only policies were renounced. Such imposition of Urdu and then the retraction of the decision resulted in a sharp decline in the English language proficiency of the general masses and also resulted in dearth of competent English language teachers, a problem that the country has still not been able to recover.

With the change of government in the year 1989, the new language policy introduced English as a mandatory subject from grade one in all public-sector schools. The private elite schools, nevertheless, continued with their English only syllabi advancing the 'rulers' and 'to be ruled' groups.

Pakistan saw a political circus from the years 1989 to 1998 which did not focus on mak- 
ing any change in or contributing to its language policies. With the government regaining its stability in 1998, a new education policy was announced that did not contribute at all to the language policy. This is significant as it shows that the government attached no significance to the role of language in education. Consequently, private English MoI schools elevated, as they had been established in the urban centres, while in rural areas, where almost $70 \%$ of the population lives- Urdu MoI government schools continued with Urdu as MoI in all subjects. This policy in turn limited the graduates of state run institutions to enter higher jobs as they were unable to emulate their peers who were from private elite institutions background.

In 2007, a 'white paper' on education policy was issued that maintained English being introduced as a subject from grade one in all public-sector schools. It also added that mathematics and science subjects are also to be taught through English as MoI from grade 6. Two years later, in 2009, the policy again switched back to 'Urdu only' as the MoI in all state-run schools with English being the MoI for Science and Mathematics from grade 4. Adding to this, recently, in 2015, the Supreme Court of Pakistan announced the verdict of petition to make Urdu the official language of Pakistan and that it should replace English in all domains. Since no measures had been taken over the years to promote Urdu language's growth; therefore, such a sudden change would create a lot of hurdles in the smooth running of administration. The efforts to make Urdu the official language and to stabilize it enough so it reaches the level of replacing English are being made. However, no measures, yet, have been made to promote the growth of Urdu and a hasty switch in the language policy will once again disturb not only the education system, but the entire administration as well.

\section{Present Day Attitudes toward English}

Despite Urdu being constitutionally supported and English trivialized, still, Urdu is not the 'official' language nor has it taken over English. The ambiguous language and education policies of the Pakistani government have ensued in two different types of educational systems in Pakistan. The top tiers of educational institutions, which are mostly non-state run, promote education in English; the other type of mainstream institutions use Urdu as MoI. These two medium of instructions are poles apart from each other and have been producing two different groups of people ever since the British rule. The same practice can be observed even today. This in turn has disturbed the education system, segregating students according to their competency in English language.

Private educators' disobedience of the constitutional laws has created a severe counteraction for state-run schools. Since in private schools, there is an emphasis on English language learning therefore it allows their students to develop greater proficiency in the language. Resultantly, these students perform better in higher education. Simply put, the clause of the Constitution that talks about the Urdu-English language policy is nothing but an acutely differentiating rule that discriminates and fragments the population into 'educated' and 'uneducated' masses. Nevertheless, English language proficiency is considered to be one of the most outstanding status symbols in the Pakistani society.

Such a situation in turn has caused a 'voluntary shift' because of which negligence 
of one's own language has become common among the masses as they learn Urdu, and mostly English for pragmatic purposes. "What happens is that market conditions are such that one's language becomes deficit on what Bierrre Bourdieu, the French sociologist, would call cultural 'capital' " (Rahman, 1996).

\section{Consequences of the Spread of English}

Drake (1984) has observed, in connection with language maintenance and shift in the United States, that the 'best predictor of future social behaviour is past social behaviour, all other things being equal' (p.146). Likely, the current situation and the present-day attitude of the people of Pakistan towards their mother tongues and English language is an indication of the fate of the languages Pakistanis choose to speak or disregard. Whichever language they disregard, or are disregarding will eventually die. O'Rahilly (1932), the Irish dialectologist and phonetician, took a harsh view of linguistic demise generally: 'When a language surrenders itself to foreign idiom, and when all its speakers become bilingual, the penalty is death' (p.121).

All languages have the tendency to diffuse into a stronger language, or to undergo the influence of a stronger language - stronger in terms of the opportunities and the prestige that language offers. The attitude of the speakers towards their language, their language loyalty, is what ultimately matters. Such is the consequence of the spread of English not only in Pakistan, but all across the globe. The weak languages are surrendering to the stronger languages. "These are languages with diminishing numbers of speakers, especially numbers who speak the language as their mother tongue" (Myers-Scotton, 2005). The stronger, state-promoted, languages are imposing their power and challenging the endangered and indigenous languages. And the reason of the special concern academics and language planners have is the fate of these endangered languages. English exerts considerable pressure on the languages categorized under super central languages, they in turn pressurize the central and then the peripheral languages are the ones which are at the utmost risk.

In Pakistan, it is not just the linguistic competition that English has given birth to, but, as addressed earlier, it has also created a number of social classes on the basis of the level of proficiency in English language. These classes are the reason why speakers of the local indigenous varieties, in their attempt and wish to reach a higher status in the society give up on their language, which at first results in language attrition, then language shift and ultimately in the death of their language.

Such attitudes of speakers are having a coercive effect on Pakistani languages. Urdu is safer as compared to other languages because it has large number proficient users and also as it is widely used in lower level/staff jobs, it is used by the media, in education, courts, commerce and other social and personal domains in Pakistan. However, Urdu too is not completely safe from the influence of English. There have been a great number of borrowings from English to Urdu, challenging Urdu's uniqueness. Code-switching, code mixing and borrowings; which are supported and promoted by Pakistani Urdu media are also threatening the purity of Urdu. A lot of English equivalent words are used in 
place of Urdu words by people without considering the fact that Urdu itself does have an alternative for that word too. Language growth of Urdu, in terms of increasing its lexicon is close to nil.

Punjabi, because of a huge number of people using it, is a big language and chances are that it will survive despite the neglect it faces from its speakers and also as it is used not only in Pakistan but also in the Indian Punjab by many powerful and influential users, what is of even more significance is that it is the language of private pleasure as is used in songs, jokes. Since a lot of people use it in this manner, it does not appear to be in any immediate and real danger.

Sindhi is a fortunate language as its speakers and users take high pride in promoting and using it. They are in power and are influential in the Sindh province and they also make use of Sindhi language sustaining its vitality. It is a scripted and well documented language. Likewise, Pashto speakers also take pride in their language and use it. However, Pashto is not used in academic domains and nor in the domains of power in Pakistan; but its speakers see their language as their asset, as an identity marker. Moreover, Pashto is also used in some power domains in Afghanistan. Therefore, predictions about the survival of Pashto can also be made. Nevertheless, this survival will be challenged by the code-switching practices of many educated Pashto speakers who switch back and forth between Pashto and Urdu or English. Thus, Pashto is also under some pressure as changes occur due to such language contacts.

Balochi is not a large language as it is constantly challenged by Urdu. However, there is considerable sense, awareness and knowledge among some educated Baloch that their languages must be safeguarded. Since it is not used in the domains of power, and is not spoken by any group outside Pakistan as well, it might sustain in the private domain. However, it is likely to be highly influenced by Urdu and might become much Urduized.

The major languages of Pakistan: Urdu, Sindhi, Punjabi, Balochi, Pashto and Siraiki, are not tremendous pressure or near to extinction. Most of these languages are used not only within, but also outside Pakistan. Figure 2 presents the global status of the six major

Figure 3

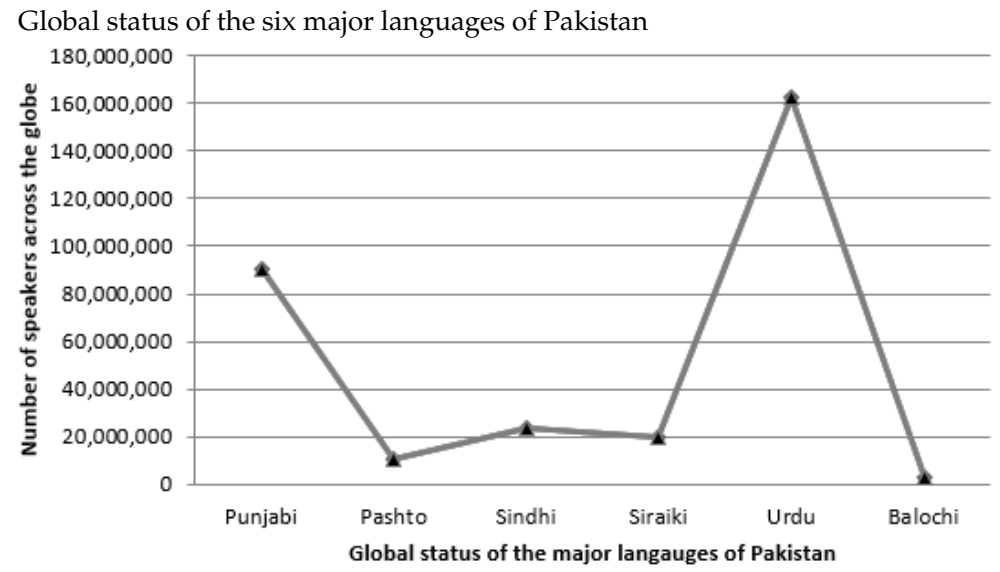


languages of Pakistan which is inclusive of non-Pakistani speakers of these languages.

Table 2 summarizes the percentage of speakers, in the world, of the six major languages of Pakistan.

\begin{tabular}{lc}
$\begin{array}{l}\text { Table } 2 \\
\text { Pakistani Languages }\end{array}$ \\
\hline Language & $\begin{array}{l}\text { Percentage of speakers } \\
\text { across the globe }\end{array}$ \\
\hline Urdu & $2.10 \%$ \\
Punjabi & $1.19 \%$ \\
Sindhi & $0.31 \%$ \\
Siraiki & $0.26 \%$ \\
Pashto & $0.14 \%$ \\
Balochi & $0.04 \%$ \\
\hline
\end{tabular}

It is the more than fifty endangered languages of Pakistan, mostly used in the North of Pakistan, which are under tremendous pressure Rahman (2006) and according to a UNESCO Project (2011), around 27 languages spoken in Northern Areas, Kashmir, Khyber Pakhtunkhwa and surrounding border areas of Pakistan are facing immediate extinction. The Karakorum Highway, which has linked these areas to the plains, has put much pressure on these languages. Urdu and English words have already made their ways in Shina and Burushaski and, as many people from Gilgit-Baltistan migrate to the cities, they are shifting from their mother tongues to Urdu. Other Pakistani indigenous languages that are close to extinction are: Chilliso, Domaaki, Gowro, Ushojo, Yidha, Phalura, Gawar-bati, and Ormuri. As Figure 3 explains, it is only 12\% of the Pakistani languages that are safe; the other $88 \%$ languages are under considerable pressure. Here, 'safe' suggests that the language is spoken by all generations, intergenerational transmissions is uninterrupted; 'vulnerable' means that most people speak the language but it may be restricted to certain domains; 'definitely endangered' are the ones that children no longer learn the language as their mother tongue; 'critically endangered' languages are spoken by elderly of that linguistic group and is not transmitted to the new generation, they neither understand nor speak it; and 'extinct' languages are those which have no speakers left.

Figure 4

Status of Pakistani languages within the country (Ethnologue 2016)

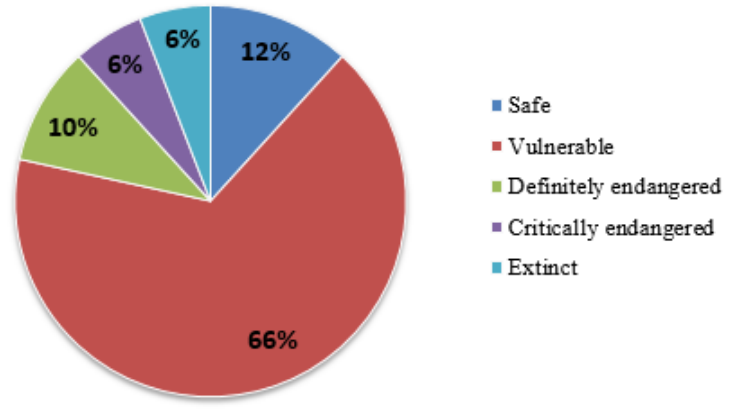




\section{Implications/Future of English in Pakistan}

As a consequence of globalization and spread of English, an increasing pressure has been exerted on all the languages across the world including Pakistan, an increasing awareness to safeguard one's own language, culture and heritage can also be observed. This is a positive change witnessed not only outside Pakistan, but within Pakistan too. People are now becoming aware of their language rights.

Language rights are an issue specifically in regards to endangered languages and indigenous minorities. A question here rises, are language rights part of human rights? Some academics, especially those involved with language education for minority groups, argue that language rights are just as important as any other "basic" rights SkutnabbKangas (2008). Therefore, conferences are now being arranged, papers are being written by the native speakers of these endangered languages to rescue their fading languages. Recently, a conference for the safeguard of Pahari language was arranged in the UK, a language association for Burushaski and Shina speakers have now been set in Karachi; codification of Kundal Shahi has also begun. However, these attempts can also benefit in slowing down the process of the extinction of the indigenous languages but if the speakers' attitudes toward their language are disloyal, the fate of that language is inevitably death.

English, as it is spreading all over the world and is offering better prospects to its knower, is likely to do the same in Pakistan. The spread of English is undeniable and hence Pakistan, as well, will soon be Englishized. However, this process may be slowed down because of the immature political circus and the government's indecisiveness over the issues of language policies. It is essential for the Pakistani government to realize that the country has already suffered a dearth in competing with the world because of not being proficient in English language.

The future of English in Pakistan, just like any other ESL country, is bright. The change in language policies might affect its rapid growth but cannot stop its spread. Even in 69 years of Pakistan's history, Urdu language has still not been able to replace English for official purposes and considering the minimal efforts being made to expand the lexicon and domains of Urdu language's use; it is very unlikely to replace English in near future.

Due to the increase in the number of business trades between China and Pakistan, Chinese is making its way to the urban centres of Pakistan. Karachi University has now made the Chinese language a compulsory subject alongside English and Urdu. Moreover, Chinese companies set in Pakistan are offering very good remuneration packages to those who know their language. It is clear that Chinese language is also paving its way for spread but this spread cannot be and will not be as effective and large-scale as the spread of English language is. It still has a long way to go. The global popularity of English is no immediate danger, neither on an international level nor at the national level in Pakistan. Therefore, if the world and Pakistan specifically, continues to develop as expected, the dislodgement of English as an official language in Pakistan and as a world language seems improbable. Nevertheless, a Pakistani variety of English, that has already emerged, is very likely to develop rapidly. This variety is expected to be different from the ENL varieties and is likely to be similar to the Indian variety of English, especially with respect 
to phonology.

English in future, in Pakistan, is probably going to see variation as it has already begun to experience. It is going to neither replace Urdu, especially in media and courts, nor will the Urdu language replace English in near future. However, considering the facts and figure, other regional and indigenous languages are very likely to have a hard time maintaining their language and sticking to their own variety.

\section{Conclusion}

As a result of perhaps either government's act of following the colonial legacy or because of globalization, there has been an exceptional pressure exerted on all other languages because of the overwhelming expansion of English across the globe and its impact on Pakistan and its regional languages. However, such a situation has also given birth to an extended language awareness resulting in advancements to safeguard their languages. It has also resulted in an increased number of English language learners in Pakistan. Such a situation is implicative of financially unstable mass being under more pressure than ever as it is not possible for them to afford expensive English medium education.

It seems impractical to stop or change the flow of the trend of globalization; however, it is possible to demote subtractive bilingualism and support additive bilingualism. This concept promotes adding to the knowledge and usage of language(s) and learning more rather than losing a language for the benefit of another. The skills and competency of one's language must be retained and a sense of pride must also be felt in our own languages while learning other language(s) to gain power and for other self-benefits. In order to achieve this, the state and our education system should promote the concept of linguistic rights.

It is time we realize the value of our languages and that in Pakistan the actual requirement is of promotion rights for our languages. Alongside, a balanced, just, and fair schooling system that promotes equality in serving education and that teaches Urdu and English to all the learners equally which is of course different and better from the way it is done now. Taking these steps will protect us from creating and formulating unstable policies and also from their harmful linguistic and extra-linguistic effects.

It is time we realize that in Pakistan the actual requirement is of promotion-oriented rights for our languages. Along with this, a balanced and fair schooling system that promotes equality in serving education and that teaches English and Urdu equally to all children and not as it is done now-very well to the elite and very badly to all others. Taking such steps will help save us from the more unstable policies and their harmful linguistic effects.

The following, 'My Language', is a very moving poem by an Evenki poet, Alitet Nemtushkin, translated and published by UNESCO, summarizes the apprehension of speakers of endangered languages. 


\section{References}

British Council Pakistan. (2012). Can English Medium Work in Pakistan? Lessons from Punjab. Retrieved from https://www.teachingenglish.org.uk/sites/ teacheng/files/Language $\% 20$ In\%20Education\%20in\%20Pakistan.pdf

British Council Pakistan. (2013). Can English Medium Work in Pakistan? Lessons from Punjab. Retrieved from https://www.britishcouncil.pk/sites/default/ files/peeli_report_0.pdf

British Council Pakistan, Pakistan Institute of Development Economics, Islamabad. (2015). Skills Disconnect in Sindh. Retrieved from https: / / www . britishcouncil .pk/sites/default/files/skill_disconnect_in_sindh.pdf

Coleman, H. (2010). The English language in development. London: British Council. Retrieved from http://www.teachingenglish.org.uk/transform/ books/english-language-development

Coleman, H. (2011). Dreams and realities: Developing countries and the English language. British Council. Retrieved from http://www.teachingenglish.org.uk/ transform/books/dreams-realities-developing-countries-English -language

Cooper, R. L. (1989). Language planning and social change. Cambridge University Press.

Drake, G. (1984). Problems of language planning in the United States. In Edwards, J. (ed). linguistic minorities, policies and pluralism. London: Academic Press.

Ethnologue. (1989). Languages of the world. Retrieved from https: / / www . et hnologue . com/language/pks

Galloway, N., \& Rose, H. (2015). Introducing global englishes. New York: Routledge.

Government of Pakistan. (2016). Population Census Organization. Islamabad: Statistics Division, Ministry of Economic Affairs \& Statistics. Available online at http://www.census.gov.pk.

Graddol, D. (1997). The future of English?: A guide to forecasting the popularity of the English language in the 21st century. London: British Council.

Jinnah, M. A. (1989). Speech at a public meeting at Dacca, 21st March. in Quaid-I-Azam Mohammad Ali Jinnah: Speeches and statements 1947-8. Islamabad: Government of Pakistan, Ministry of Information and Broadcasting, 1989.

Kachru, B. B. (1986). The alchemy of English: The spread, functions, and models of non-native Englishes. Champaign: University of Illinois Press.

Mehboob, A. (2002). No english, no future! Language policy in Pakistan. In O.S. Gyasi. $\mathcal{E} H$. Beverley (Eds.), political independence with linguistic servitude: The politics about languages in the developing world. New York: Nova Science Publishers.

Myers-Scotton, C. (2005). Multiple voices: An introduction to bilingualism. Australia: Blackwell Publishing.

O'Rahilly, T. F. (1932). Irish dialects past and present: With chapters on Scottish and Manx. Dublin: Dublin Institute for Advanced Studies.

Powell, R. (2002). Language planning and the British Empire: Comparing Pakistan, Malaysia and Kenya. Current Issues in Language Planning, 3(3), 205-279.

Rahman, T. (1996). Language and politics in Pakistan. Karachi: Oxford University Press. 
Rahman, T. (2004). Denizens of alien worlds: A study of education, inequality and polarization in Pakistan. Oxford and Karachi: Oxford University Press.

Rahman, T. (2006). Language policy, language vitality and multilingualism in Pakistan. In A. Saxena \& L. Borin (Eds.), trends in linguistic: Lesser known languages of South Asia. Language in Society, 38(2), 233-258.

Rahman, T. (2010). Pakistani english. Islamabad: Quaid - $i$ - Azam University.

Rehman, K. A., \& Baart, J. L. (2005). A first look at the language of Kundal Shahi in Azad Kashmir. IL International.

Rubin, J. (1983). Bilingual education and language planning. In Kennedy, C. (Ed.) language planning and language education. London: George Allen \& Unwin.

Seargeant, P., \& Erling, E. J. (2011). The discourse of 'English as a language for international development': Policy assumptions and practical challenges. In H. Coleman (ed.), Dreams and realities: Developing countries and the English language. London: British Council.

Shamim, F. (2011). English as the language for development in Pakistan: Issues, challenges and possible solutions. In H. Coleman (ed.), Dreams and realities: Developing countries and the English language. London: British Council.

Skutnabb-Kangas, T. (2008). Human rights and language policy in education. In S. May E S. Hornberger (Eds.), language policy and political issues in education: Encyclopedia of language and education. New York: Springer.

UNESCO Project. (2011). Atlas of the Worlds Languages in Danger. Retrieved from http: / / unesdoc. unesco.org/images/0019/001924/192416e.pdf

Wedell, M. (2011). More than just 'technology': English language teaching initiatives as complex educational changes. In H. Coleman (ed.), dreams and realities: Developing countries and the English language. London: British Council. 